\title{
Prognosis in hypertrophic cardiomyopathy with asymmetric septal hypertrophy
}

\author{
Dwarka Wadehra ${ }^{1}$, Rolf M. Gunnar ${ }^{1}$ and Patrick J. Scanlon ${ }^{2}$ \\ ${ }^{1}$ Department of Medicine, ${ }^{2}$ Section of Cardiology, Loyola University Stritch School of Medicine and Veterans \\ Administration Hospital, Hines and Maywood, Illinois, USA.
}

\begin{abstract}
Summary: Hypertrophic cardiomyopathy with asymmetric septal hypertrophy is not an uncommon disorder in the older adult population, and frequently masquerades as coronary artery disease. Most symptomatic patients with hypertrophic cardiomyopathy diagnosed as adults have a benign course with mild disability lasting for many years. Associated significant obstructive coronary artery disease was present in $22 \%$ of our patients and probably represents the cause of symptoms and, therefore, investigation in some of our patients rather than a high incidence of coronary disease in patients with asymmetric septal hypertrophy. Sudden death was not common in our patients (3.6\%) and occurred at 11 years after diagnosis in a patient with associated coronary artery disease and 4 years after diagnostic study in a patient with uncomplicated hypertrophic cardiomyopathy.
\end{abstract}

\section{Introduction}

It has been the general consensus that patients with hypertrophic cardiomyopathy and asymmetric septal hypertrophy have an annual mortality rate of 3-5\% per year (Hardarson et al., 1973; Frank \& Braunwald, 1968; Shah et al., 1974). Many of these patients die suddenly and supposedly of ventricular arrhythmias. It has been our impression that the mortality in the patients we followed has been considerably less than this and for this reason, we considered it useful to review our own experience.

\section{Patients}

This review includes 58 patients seen at Loyola University Medical Center since 1973. The diagnosis of hypertrophic cardiomyopathy with asymmetric septal hypertrophy was established by characteristic haemodynamic, angiographic or echocardiographic criteria (Frank \& Braunwald, 1968; Doi et al., 1980; Simon et al., 1967). The mean age of the patient population was 51.2 , with a range of 14 to 72 years. There were 31 males and 27 females. The duration of follow-up from onset of symptoms averaged 9.3 years with the shortest 6 months and the longest 29 years. Follow-up at our institution from the time of cardiac catheterization averaged 5.6 years, with a range from 1 month to 11 years.

Correspondence: R.M. Gunnar, M.D., F.A.C.P., Department of Medicine, Loyola University Medical Center, 2160 S. First Avenue, Maywood, Illinois 60153, USA.

\section{Symptoms}

The patients presented to us with symptoms of chest pain in 49 , dyspnoea in 35 , palpitations in 28 , and syncope in 5 of the patients. There was one young patient who was asymptomatic, and presented with an abnormal electrocardiogram.

\section{Electrocardiogram and echocardiogram}

The echocardiogram showed evidence of asymmetric septal hypertrophy and, in a majority of patients, there was systolic anterior motion of the mitral valve. The criteria for the ratio of septal to posterior wall thickness was $1.5: 1$ or more and this was met in most. The electrocardiogram demonstrated normal sinus rhythm in all except four patients who had atrial fibrillation as their basic rhythm. Thirty-six of the 58 showed evidence of left ventricular hypertrophy by electrocardiograms, 6 had bundle branch block (4 left, 2 right) and 6 had intraventricular conduction delay of

Table I Functional classification in 58 patients with hypertrophic cardiomyopathy at follow-up

$\begin{array}{lr}\text { Class I } & 31 \\ \text { Class II } & 15 \\ \text { Class III-IV } & 4 \\ \text { Dead } & 6 \\ \text { Lost } & 2\end{array}$

The Fellowship of Postgraduate Medicine, 1985 
the leftward type. There were 8 patients with infarct patterns on their electrocardiogram. Five patients had first degree heart block. There were only 5 patients whose electrocardiograms were interpreted as normal.

\section{Cardiac catheterization and angiography}

Fifty-seven of the 58 patients were subjected to cardiac catheterization; 23 had no resting gradient, 13 had a resting gradient between 10 and $39 \mathrm{~mm} \mathrm{Hg}, 6$ had a gradient between 40 and $59 \mathrm{~mm} \mathrm{Hg}, 9$ had a gradient of 60 to $99 \mathrm{~mm} \mathrm{Hg}$, and 6 had a gradient greater than $100 \mathrm{~mm} \mathrm{Hg}$ at rest. In the 23 patients with no resting gradient, premature ventricular beats, the Valsalva manoeuvre, amyl nitrate or isoproterenol were used to induce a gradient in 20. One of these did not develop a gradient, 3 developed gradients between 10 and $39 \mathrm{~mm} \mathrm{Hg}, 3$ between 40 and $59 \mathrm{~mm} \mathrm{Hg}, 6$ between 60 and $99 \mathrm{~mm} \mathrm{Hg}$, and 7 developed gradients greater than $100 \mathrm{~mm} \mathrm{Hg}$. In three patients it was elected not to try stimulation because the diagnosis was thought established by echocardiography or angiography.

At cardiac catheterization, mitral insufficiency was present in 30 of the patients; in 15 it was considered mild, but in 15 it was considered moderate or severe. One patient had significant aortic insufficiency. Thirteen of the 57 patients had significant obstructive coronary disease (greater than $70 \%$ stenosis) in one or more of the three major arteries.

\section{Treatment and follow-up}

The treatment of these patients consisted of betablockers alone in 40 patients and calcium entry blocking agents alone in 5. Six patients received calcium entry blockers plus a beta-blocker, and one patient received a calcium entry blocker plus disopyramide. There were 3 patients who did well with no therapy.

Two patients were lost to follow-up; one patient was an alcoholic and cannot be found, the other patient has moved from the area and the referring physician could not locate this patient. One patient died in the operating room during surgery for aortocoronary bypass and valve replacement for severe mitral insufficiency. It appears that the death was due to difficulty in providing adequate myocardial protection during the surgery. One other patient had mitral valve replacement. One patient had a myotomy and aortic valve replacement at two different operative interventions. One patient had aortocoronary bypass and one patient had a pacemaker inserted.

In the follow-up period. which lasted 1 month to 11 years from the point of catheterization or up to 29 years from the onset of symptoms, 31 patients were found to be in Class I functional status, 15 patients were in Class II, 4 patients were in Class III or IV, 6 patients had died, and two patients as mentioned previously had been lost to follow-up (Table I).

\section{Deaths}

In analysing the 6 deaths, 2 of the patients died of carcinoma of the breast and both were in cardiac function Class II at the time of their death $3 \frac{1}{2}$ and 8 years after their cardiac catheterization. One patient, as mentioned above, died in the operating room during valve replacement and aortocoronary bypass. One patient who had been catheterized elsewhere and at that time found to have hypertrophic cardiomyopathy with a marked intra-cavity gradient, when seen by us had a minimal gradient of $10 \mathrm{~mm} \mathrm{Hg}$ and gave the clinical picture of dilated cardiomyopathy. He died 16 years after the onset of his symptoms, 12 years after the onset of his treatment and the original diagnosis, but 2 years after our catheterization, which established the progression to severe left ventricular dysfunction.

Only 2 of the 56 patients whom we followed had sudden death. One patient died suddenly 11 years after the diagnosis was established. This patient had had aortocoronary bypass for severe three vessel disease 10 years before death and had a resting gradient at catheterization of $30 \mathrm{~mm} \mathrm{Hg}$. The other patient who died suddenly did so 4 years after our study; he had been symptomatic for 23 years, had a resting gradient of $88 \mathrm{~mm} \mathrm{Hg}$ at the time of the study, and had been on treatment with propranolol. This, then, presents us with two sudden deaths, one of which could be explained on the basis of coronary disease, in this population of patients who had been followed for as long as 29 years after the onset of their symptoms.

\section{Discussion}

There are several possible reasons for the rather benign course in patients with hypertrophic cardiomyopathy and asymmetric septal hypertrophy in our series. Loyola Medical Center is a referral centre which is well recognized for treatment of coronary artery disease and for dilated cardiomyopathy, but does not particularly gather in patients who are recognized as having complicated hypertrophic cardiomyopathy. This, therefore, makes our patient population similar, we feel, to that of the average cardiologist seeing patients who are suspected of having coronary disease or who have an unexplained murmur. We perhaps see additional patients because of suspicion of coronary artery disease as the cause of their chest pain. This would then explain the older age 
of the patients in our series.

In the multicentre study reported by Shah et al. (1974) $52 \%$ of the patients were less than 30 years old. Only $26 \%$ of their patients were over 40 years old while $86 \%$ of our patients were over 40 years of age. Although Shah et al. (1974) did not conclude that sudden death was more common in their younger patients, they did find a reduction in this outcome in patients over age 40. Hardarson et al. (1973) demonstrated a higher incidence of sudden death in the young, particularly in males with the familial form of the disease. Maron et al. (1978) also described a 'malignant' form of the disease with a high incidence of sudden death in young males. They also showed young age to be a significant factor in the profile of patients with sudden death (Maron et al., 1978b, 1982).

Most of our patients were treated with beta blockers and this has been associated with improved protection against sudden death. Frank et al. (1978, 1983a) showed a significant decrease in the incidence of sudden death in the patients treated with propranolol. They related this to a significant decrease in potential-

\section{References}

CLARK, C.E., HENRY, W.L. \& EPSTEIN, S.E. (1973). Familial prevalence and genetic transmission of idiopathic hypertrophic subaortic stenosis. New England Journal of Medicine, 289, 709.

DOI, Y.L., McKENNA, W.J., GEHRKE, J., OAKLEY, C.M. \& GOODWIN, J.F. (1980). M mode echocardiography in hypertrophic cardiomyopathy: diagnostic criteria and prediction of obstruction. American Journal of Cardiology, 45, 6.

FRANK, S. \& BRAUNWALD, E. (1968). Idiopathic hypertrophic subaortic stenosis: clinical analysis of 126 patients with emphasis on the natural history. Circulation, 37, 759.

FRANK, M.J., ABDULLA, A.M., CANEDO, M.I. \& SAYLESS, R.E. (1978). Long term medical management of hypertrophic obstructive cardiomyopathy. American Journal of Cardiology, 42, 993.

FRANK, M.J., ABDULLA, A.M., WATKINS, L.O., PRISANT, L. \& STEFADOUROS, M.A. (1983a). Long term medical management of hypertrophic cardiomyopathy: usefulness of propranolol. European Heart Journal, 4 (Suppl F), 155.

FRANK, M.J., STEFADOUROS, M.A., WATKINS, L.O., PRISANT, L.M. \& ABDULLA, A.M. (1983b). Rhythm disturbances in hypertrophic cardiomyopathy: relationship to symptoms and the effect of 'complete' beta blockade. European Heart Journal, 4 (Suppl F), 235

HARDARSON, T., CURIEL, R. DE LA CALZADA, C.S. \& GOODWIN, J.F. (1973). Prognosis and mortality of hypertrophic cardiomyopathy. Lancet, ii, 1462

KISHIMOTO, C., KABURAGI, T., TAKAYAMA, S., YOKOYAMA, S., HANYU, I., TAKATSU, Y. \& TOMIMOTO, K. (1983). Two forms of hypertrophic cardiomyopathy distinguished by inheritance of HLA haplotypes and left ventricular outflow tract obstruction. American Heart Journal, 105, 988. ly lethal arrhythmias (Frank et al., 1983b). On the other hand, McKenna (1983) was unable to show a positive effect of beta-blockade on sudden death and advocated the use of amiodarone, an agent we have not used in our patients with this disease. Maron et al. (1982) were also unable to demonstrate an effect of propranolol on sudden death in their retrospective study. There is a possibility that our experience is geographic and, by heredity, our patients are a somewhat different group, but this cannot be established. Clark et al. (1973) described genetic transmission of the disease and Kishimoto et al. (1983) more recently, have shown a familial form of the disease linked to inheritance of HLA haplotypes and this may identify a more malignant form of the disease. The older age of our patients would suggest that, in most, the disease was not the familial type. We are not alone in describing a benign course for this disease. Parker (1969) and Shapiro \& Zezulka (1983), working from smaller series and shorter follow-up, have also suggested that this disease has a more benign course than previously thought.

MARON, B.J., LIPSON, L.C., ROBERTS, W.C., SAVAGE, D.D. \& EPSTEIN, S.E. (1978a). 'Malignant' hypertrophic cardiomyopathy: identification of a subgroup of families with unusually frequent premature deaths. American Journal of Cardiology, 41, 1133.

MARON, B.J., ROBERTS, W.C., EDWARDS, J.E., MCALLISTER, H.A., JR., FOLEY, D.D. \& EPSTEIN, S.E. (1978b). Sudden death in patients with hypertrophic cardiomyopathy: Characterization of 26 patients without functional limitation. American Journal of Cardiology, 41, 803.

MARON, B.J., ROBERTS, W.C., EPSTEIN, S.E. (1982). Sudden death in hypertrophic cardiomyopathy: A profile of 78 patients. Circulation, 65, 1388.

MCKENNA, W.J. (1983). Arrhythmia and prognosis in hypertrophic cardiomyopathy. European Heart Journal, 4 (Suppl F), 235.

PARKER, B.M. (1969). The course in idiopathic hypertrophic subaortic stenosis. Annals of Internal Medicine, 70, 903.

SHAH, P.M., ADELMAN, A.G. \& WIGLE, F.D. (1974). The natural (and unnatural) history of hypertrophic obstructive cardiomyopathy. A multicenter study. Circulation Research, 34 \& 35 (Suppl II), 179.

SHAPIRO, L.M. \& ZEZULKA, A. (1983). Hypertrophic cardiomyopathy: a common disease with a good prognosis. Five year experience of a district general hospital. British Heart Journal, 50, 530.

SIMON, A.L., ROSS, J., JR. \& GAULT, J.H. (1967). Angiographic anatomy of the left ventricle and mitral valve in idiopathic hypertrophic subaortic stenosis. Circulation, 36, 852. 